\title{
NÍVEL DE EVIDENCIAÇÃO DE CUSTOS E INVESTIMENTOS AMBIENTAIS E LEGIBILIDADE DOS RELATÓRIOS DA ADMINISTRAÇÃO DE EMPRESAS DO SETOR DE PAPEL E CELULOSE
}

\section{LEVEL OF EVIDENCE OF ENVIRONMENTAL COSTS AND INVESTMENTS AND LEGIBILITY OF PAPER AND CELLULOSE SECTOR ADMINISTRATION REPORTS}

\section{RESUMO}

Este estudo tem como objetivo analisar a relação entre o nível de evidenciação de informações de custos e investimentos ambientais e o grau de legibilidade dos Relatórios da Administração de empresas do setor de papel e celulose listadas na Brasil Bolsa Balcão [B] $]^{3}$ entre os anos de 2014 a 2018. O nível de evidenciação foi calculado a partir de categorização realizada a partir de análise de conteúdo e o grau de legibilidade foi calculado a partir do Gunning Fog Index. Os resultados encontrados indicaram que as empresas, por mais que tenham evoluído o nível de evidenciação em consideração a estudos semelhantes, não responderam, em sua totalidade, os questionamentos abordados na metodologia. Além disso, a maioria das empresas apresentaram grau de legibilidade considerado ilegível em todos os anos compreendidos pela pesquisa. A regressão linear simples indicou que o nível de evidenciação e o grau de legibilidade estão negativamente relacionados, apontando que, conforme o nível de evidenciação diminui há um aumento no grau de legibilidade das informações de cunho ambiental. Esses resultados podem indicar que o grau de legibilidade elevado pode tornar subjetiva a informação que é transmitida. Outro ponto a ser discutido a respeito dos resultados, é que as empresas podem deixar a evidenciação ambiental com linguagem mais rebuscada, prejudicando a compreensibilidade do usuário da informação.

Palavras-chave: Legibilidade. Evidenciação. Investimentos e custos ambientais. Papel e celulose.

\begin{abstract}
This study aims to analyze the relationship between the level of disclosure of information on environmental costs and investments and the degree of readability of the Management Reports of companies in the paper and cellulose sector listed in Brasil Bolsa Balcão [B] ${ }^{3}$ between the years of 2014 to 2018. The level of disclosure was calculated from categorization based on content analysis and the degree of readability was calculated from the Gunning Fog Index. The results found indicated that the companies, even though the level of disclosure has evolved in consideration of similar studies, have not fully answered the questions addressed in the methodology. In addition, most companies showed a degree of legibility considered unreadable in all the years covered by the survey. Simple linear regression indicated that the level of disclosure and the degree of readability are negatively related, pointing out that, as the level of disclosure decreases, there is an increase in the degree of legibility of environmental information. These results may indicate that the high degree of readability can make the information that is transmitted subjective. Another point to be discussed regarding the results, is that companies can leave environmental disclosure with more elaborate language, impairing the comprehensibility of the information user.
\end{abstract}

Keywords: Readability. Disclosure. Environmental investments and costs. Paper And Cellulose.

\section{Fabio Henrique Voigt}

Graduado em Ciências Contábeis pela Universidade Estadual de Ponta Grossa (UEPG). Contato: Praça Santos Andrade, n. ${ }^{\circ}$ 01 - Centro - CEP 84010-919 - Ponta Grossa - PR. Fone: 42-3220-3392 (departamento) 42-3320-3393 (colegiado). E-mail: fabiovoigt1@gmail.com

\section{João Victor Machado}

Graduado em Ciências Contábeis pela Universidade Estadual de Ponta Grossa (UEPG). Contato: Praça Santos Andrade, n. ${ }^{\circ}$ 01 - Centro - CEP 84010-919 - Ponta Grossa - PR. Fone: 42-3220-3392 (departamento) 42-3320-3393 (colegiado). E-mail: jvictormach@gmail.com

\section{Alison Martins Meurer}

Doutorando em Contabilidade pela Universidade Federal do Paraná (UFPR). Mestre em Contabilidade pela Universidade Federal do Paraná (UFPR). Especialista em Avaliação do Ensino e da Aprendizagem pela Universidade do Oeste Paulista (UNOESTE). Graduado em Ciências Contábeis pela Universidade Tecnológica Federal do Paraná (UTFPR). Docente do curso de Ciências Contábeis na Universidade Estadual de Ponta Grossa (UEPG). Contato: Praça Santos Andrade, n. ${ }^{\circ}$ 01 - Centro - CEP 84010-919 - Ponta Grossa - PR. Fone: 42-3220-3392 (departamento) 42-3320-3393 (colegiado). E-mail: alisonmmeurer@gmail.com 


\section{INTRODUÇÃO}

Com o passar dos anos, as empresas vêm se adequando às novas exigências do mercado e das legislações ambientais, inserindo ferramentas que auxiliam na redução dos impactos ambientais gerados pela sua atividade operacional (Silva, Theis \& Schreiber, 2016). Especificamente em relação a indústria de papel e celulose, foco desta pesquisa, o anexo VIII da Lei $n^{\circ}$ 10.165/2000, que trata da Política Nacional do Meio Ambiente, indica que este setor desenvolve atividades que são consideradas potencialmente poluidoras, visto que o potencial de poluição (PP) e o grau de utilização (GU) de recursos naturais é considerado alto. Tal constatação tem despertado preocupações em diversos pesquisadores ao longo dos anos que têm desenvolvido pesquisas a fim de verificar as ações evidenciadas pelas empresas da indústria de papel e celulose na mitigação de seus impactos ambientais, sendo que os achados apresentam-se plurais.

Por exemplo, Machado et al. (2015) constataram a não evidenciação de custos ambientais por empresas listadas na BM\&FBovespa no segmento de papel e celulose no período de 2008 e 2009. Por outro lado, Fonseca et al. (2016) evidenciaram uma evolução em relação as mesmas empresas no período de 2010 a 2014, quanto a divulgação nas notas explicativas, tanto na qualidade, como na quantidade de evidenciação dos custos ambientais deste setor.

Referente ao conteúdo das divulgações, o Instituto Brasileiro de Governança Corporativa (IBGC, 2015, p. 74) cita que os relatórios financeiros "devem identificar os insumos, produtos/serviços e o impacto das atividades na sociedade em geral e no meio ambiente”. Essa conotação apresentada pelo IBGC pode ser embasada pelo fato de muitos usuários da informação contábil terem interesses na disclosure relacionada as questões ambientais, como: ativos ambientais, passivos ambientais, danos causados ao meio ambiente e suas consequências, entre outros (Bremenkamp et al., 2011). Assim, a deficiência informacional faz com que os riscos e impactos ambientais não sejam avaliados de maneira fidedigna, provocando viés na análise das informações e ocultando aspectos que poderiam ser relevantes para a tomada de decisão dos usuários da informação.

Logo, a evidenciação quando realizada de forma compreensível auxilia os diferentes stakeholders a mapear o comportamento organizacional, e nesse contexto tem-se a importância da legibilidade. Lupton (2003) relaciona a legibilidade com a capacidade do indivíduo em compreender informações apresentadas em forma textual. Li (2008) destaca que as empresas podem minimizar a legibilidade para ofuscar resultados e informações negativas sobre a organização. Cruz Junior (2018) afirmam que a capacidade de divulgação das empresas por meio de sua estrutura textual pode contribuir para obter maior compreensão da maneira como essas informações cumprem com seus objetivos informacionais de auxiliar no processo decisório, tendo a característica qualitativa da compreensibilidade como pilar. Portanto, a legibilidade pode ser relacionada diretamente com a capacidade dos diferentes stakeholders obter e compreender informações úteis para a tomada de decisão (Du \& Yu, 2020).

A partir da observação de que existe um cenário evolutivo tanto no nível de evidenciação de informações de custos e investimentos ambientais, como na legibilidade dos relatórios cujas informações estão contidas, nota-se que é possível indagar sobre a existência de um possível padrão entre a divulgação de informações ambientais e sua influência no respectivo grau de legibilidade, por meio da seguinte questão: Qual a relação entre o nivel de evidenciação de informações de custos e investimentos ambientais e o grau de legibilidade dos Relatórios da Administração de empresas do setor de papel e celulose listadas na Brasil Bolsa Balcão [B] ${ }^{3}$ ? Assim, esse estudo objetiva analisar a relação entre o nível de evidenciação de informações de custos e investimentos ambientais e o grau de legibilidade dos Relatórios da Administração de empresas do setor de papel e celulose listadas na [B] $]^{3}$ entre os anos de 2014 a 2018. O Relatório da Administração é o objeto de análise desta pesquisa por ser de divulgação obrigatória e por representar um dos principais meios de comunicação da alta administração com os diferentes stakeholders.

A pesquisa justifica-se nos âmbitos social, profissional e acadêmico. Para a sociedade, a justificativa desse estudo parte de que é necessário um monitoramento em relação às atividades realizadas pelas empresas do setor de papel e celulose. Um fator determinante para a mudança de posicionamento em relação aos processos de produção, gestão e divulgação das informações é justamente a verificação de que o meio ambiente é um fator determinante para a continuidade dos negócios (Casagrande et al., 2013).

Em relação ao mercado profissional, esse estudo preocupa-se em alcançar profissionais da área Contábil, para que os forneça informações sobre a evidenciação realizada em um relatório divulgado com o conjunto de demonstrações contábeis, e que, com base na atual situação e o conhecimento de sua relevância, busquem uma evolução na elaboração desses documentos.

Referente ao contexto acadêmico, salienta-se a originalidade, pois na literatura consultada é analisada a evidenciação das informações e sua legibilidade de forma segregada, não especulando-se relação entre essas variáveis. $\mathrm{O}$ estudo sobre uma possível relação enriquece os achados na área ambiental, e também oferece apoio para que estudos semelhantes sejam realizados a fim de avançar as discussões sobre a temática, à medida que as investigações sobre legibilidade e evidenciação de informações ambientais são escassas. 


\section{REFERENCIAL TEÓRICO}

\subsection{Evidenciação Ambiental}

Entendendo que a Contabilidade Ambiental é utilizada para evidenciar e mensurar a relação das empresas com o meio ambiente, é percebido também que há gastos e ações ambientais que são provenientes da atividade operacional da organização. A mensuração e a evidenciação correta desses gastos e ações podem auxiliar a administração a focalizar medidas preventivas que podem contribuir para uma melhora de sua imagem diante da opinião pública (Tinôco \& Kraemer, 2011).

A evidenciação de eventos econômico-financeiros de cunho ambiental é uma forma da Contabilidade contribuir com o processo de preservação e proteção nessa área. As mudanças no comportamento empresarial, que se decorreram da globalização dos mercados, enriqueceram os relatórios anuais das organizações e também estimularam empresas concorrentes a realizarem ações semelhantes ou melhores que as outras, o que traz, como consequência, o benefício da sociedade como um todo (Ribeiro, 2005). Para Rover et al. (2012) a evidenciação ambiental é um meio de comunicação entre empresa e seus stakeholders, e a partir das estratégias de relacionamento entre organização e usuários da informação é que será definido o nível e conteúdo das informações ambientais divulgadas.

Nesse sentido, os relatórios que demonstram as informações financeiras das organizações potencialmente poluidoras podem ter múltiplos papéis para o usuário. Por exemplo, Clarkson et al. (2008) constataram que as informações ambientais que são divulgadas nos relatórios das organizações preveem uma associação positiva entre o desempenho ambiental de uma entidade e o seu nível de evidenciação ambiental discricionário. Rezaee e Tuo (2019) mostraram que a quantidade de evidenciação ambiental está associada negativamente aos ganhos discricionários das organizações.

Referente as informações evidenciadas, Ribeiro (2005) afirma que a evidenciação ambiental implica em questionar os seguintes pontos expostos na Figura 01.

Figura 1 - Implicações da Evidenciação Ambiental

\begin{tabular}{c|c}
\hline O quê? & Todas as informações relativas aos eventos e às transações envolvidos com a questão ambiental \\
Como? & $\begin{array}{r}\text { Com o grau de detalhamento exigido pela relevância dos valores e da natureza dos gastos, relativos à interação } \\
\text { da empresa com o meio ambiente }\end{array}$ \\
Quando? & $\begin{array}{r}\text { O registro contábil deverá ser feito no momento em que o fato gerador ocorrer, ou no momento em que houver } \\
\text { informaços adicionais e complementares }\end{array}$ \\
Onde? & $\begin{array}{r}\text { Nas demonstrações contábeis e nas notas explicativas, dependendo da extensão e da natureza das informações } \\
\text { a serem prestadas }\end{array}$ \\
\hline
\end{tabular}

Fonte: Ribeiro (2005, p. 108)

No que compete às normas referentes ao assunto, a NBC T-15 - Informações de Natureza Social e Ambiental detalha a divulgação das informações de cunho ambiental que podem ou devem ser apresentadas em seus relatórios. Destacam-se, nessa norma, os itens: investimentos e gastos com manutenção nos processos operacionais para a melhoria do meio ambiente; investimentos e gastos com a preservação e/ou recuperação de ambientes degradados; investimentos e gastos com a educação ambiental para empregados, terceirizados, autônomos e administradores da entidade; investimentos e gastos com educação ambiental para a comunidade; investimentos e gastos com outros projetos ambientais; quantidade de processos ambientais, administrativos e judiciais movidos contra a entidade; valor das multas e das indenizações relativas à matéria ambiental, determinadas administrativa e/ou judicialmente; passivos e contingências ambientais, dentre outros itens. Dessa forma, estas categorias direcionam o presente estudo, à medida que o nível de evidenciação dos relatórios tem como base essa norma considerando que quanto maior o número de itens da norma apresentados nas demonstrações das companhias, maior será seu nível de evidenciação.

Referente aos estudos anteriores, é possível encontrar diversas pesquisas que buscaram identificar a evidenciação ambiental e seu nível, no que se refere aos custos e investimentos ambientais de empresas de segmentos variados (Freitas \& Strassburg, 2007; Rover et al., 2008; Borges et al., 2010; Machado et al., 2015; Fonseca et al., 2016). Nessas pesquisas são utilizadas diferentes métricas e metodologias de análise nos relatórios divulgados, o que traz também uma variedade de resultados encontrados.

Freitas e Strassburg (2007) analisaram os investimentos e gastos ambientais das cinco maiores empresas do setor de papel e celulose do ano de 2004. Os achados indicaram que poucas informações foram evidenciadas acerca da temática, sendo que as divulgações realizadas normalmente são estritamente descritivas sem apresentar dados financeiros referentes aos investimentos e gastos ambientais.

Rover et al. (2008) tiveram como objetivo identificar as informações sobre custos e investimentos ambientais e como elas são evidenciadas pelas 34 empresas classificadas no ISE de 2006/2007. Verificou-se que a maioria das informações sobre custos ambientais foi apresentada nos Relatórios Anuais, que a maior parte dos investimentos em meio ambiente foi evidenciada nas Demonstrações Financeiras Padronizadas, e que o tipo de evidenciação quantitativa monetária foi a mais utilizada, tanto nos custos como nos investimentos ambientais. Para chegar nesse resultado, foram 
analisadas as Demonstrações Financeiras Padronizadas, o Balanço Social, o Relatório Anual e o Relatório de Sustentabilidade. Para identificar como a informação foi divulgada nesses relatórios, a evidenciação foi categorizada em quatro tipos, conforme apresentado na Figura 02.

Figura 2 -. Naturezas da evidenciação ambiental

\begin{tabular}{c|c}
\hline $\begin{array}{c}\text { Evidenciação declarativa } \\
\text { Evidenciação quantitativa } \\
\text { não-monetária }\end{array}$ & Quando a informação qualitativa é apresentada de forma puramente descritiva \\
$\begin{array}{c}\text { Evidenciação quantitativa mon- } \\
\text { etária }\end{array}$ & Quando a informação quantitativa é apresentada em números de natureza não-financeira \\
$\begin{array}{c}\text { Evidenciação quantitativa mon- quantitativa é apresentada em números de natureza financeira } \\
\text { etária e não-monetária }\end{array}$ & Quando a informação quantitativa é apresentada em números de natureza financeira e \\
não-financeira.
\end{tabular}

Fonte: Adaptado de Rover et al. (2008).

Borges et al. (2010) objetivaram investigar a evidenciação voluntária das vinte maiores empresas brasileiras de papel e celulose. No trabalho em questão, os sites das organizações e os seus Relatórios de Sustentabilidade foram analisados a fim de localizar indicadores que permitiram construir conhecimento das práticas ambientais em canais de comunicação utilizados pelas empresas pesquisadas. Para chegar no resultado, foram buscados 32 elementos de verificação da evidenciação ambiental. Dentro desses elementos, estão a reciclagem e otimização de recursos, o respeito na ocupação de solo, o reflorestamento, reserva, fomento e manejo florestal. Como resultado, verificou-se que, na maioria das instituições analisadas, as políticas ambientais são declaradas amplamente, sendo que aspectos financeiros ambientais são divulgados, em sua maioria, de forma descritiva, e não quantitativa.

Machado et al. (2015) objetivaram identificar como as empresas pertencentes ao setor de papel e celulose listadas na $\mathrm{B}^{3}$ têm evidenciado seus custos de cunho ambiental a partir de um estudo com seis empresas, no período de 2008 e 2009. Para isso, usaram a mesma métrica de Rover et al. (2008) de subdivisão em categorias dos custos ambientais. Os resultados mostraram que não houve qualquer evidenciação de custos ambientais por parte das empresas estudadas. No entanto, foi possível identificar práticas de gestão ambiental, certificações, ações socioambientais, de sustentabilidade, entre outras.

O estudo de Fonseca et al. (2016) tiveram como objetivo analisar como evoluiu, em relação a estudos anteriores, a classificação e evidenciação dos custos ambientais em empresas integrantes do setor de papel e celulose listadas no Índice de Sustentabilidade Empresarial - ISE. Para isso, foi analisado o conteúdo das demonstrações contábeis, notas explicativas e relatórios de administração e relatórios de sustentabilidade dos exercícios sociais de 2010 a 2014 . A coleta dos dados foi operacionalizada a partir da busca das palavras "custo" e "ambiente" em todos os documentos citados. Dessa forma, os resultados encontrados indicaram que as empresas evidenciam seus custos ambientais principalmente na forma qualitativa e do tipo positiva. De forma geral, pôde-se constatar uma evolução em relação a estudos anteriores tanto na qualidade, como na quantidade de evidenciação dos custos ambientais.

Assim, a partir dos estudos anteriores é possível constatar que a variação dos resultados caminha juntamente com a pluralidade das metodologias utilizadas. Quanto mais específica e complexa a metodologia, mais detalhado é o resultado.

\subsection{Grau de Legibilidade}

Segundo Dias Filho e Nakagawa (2001), a Contabilidade tem como função básica a comunicação, na medida em que se é reconhecido que sua missão é identificar, mensurar e comunicar os eventos que influenciam o patrimônio da entidade. De acordo com os autores, poucas pesquisas têm sido feitas com o caráter investigativo, no que se refere à linguagem utilizada na evidenciação contábil e se essa linguagem permite uma compreensão satisfatória dos fatores que permitem influenciar as decisões econômico-financeiras dos usuários da Contabilidade.

Silva e Rodrigues (2010), afirmam que os relatórios divulgados por empresas têm uma influência significativa na percepção dos usuários, especialmente no que se refere à observação de pontos como a liquidez e competitividade frente ao mercado. A comunicação dos eventos econômicos, de acordo com Silva e Fernandes (2009), deve ser tempestiva e precisa, a fim de permitir a tomada de decisão adequada pelos usuários da Contabilidade. O IBGC (2015) fomenta que a comunicação entre as partes, sendo elas a entidade e os usuários das informações divulgadas pela Contabilidade da entidade, não deve restringir-se ao desempenho financeiro, mas também contemplar demais fatores que norteiam a ação empresarial, pois uma boa comunicação entre as duas partes proporciona um clima de confiança entre as empresas e os stakeholders.

Atrelada a qualidade da comunicação textual tem-se a legibilidade. Lourenço (2011) cita que pode-se adotar como consenso que o termo legibilidade diz respeito a forma das letras, ao caractere individual, aos espaços entre palavras, tamanho das palavras, velocidade de leitura, fatores ambientais, nível de fadiga do leitor, experiência do leitor e habilidades intelectuais capazes de interferir no processo de compreensão de um determinado texto.

Admitida a importância da legibilidade das demonstrações para os usuários da Contabilidade, se faz necessário um recurso para realizar a mensuração do grau de legibilidade para fins de comparação ao longo do tempo e comparação 
entre as empresas em geral. Dentre as ferramentas utilizadas para essa mensuração, está o método de legibilidade Flesch. Esse método foi utilizado por Silva e Fernandes (2009), para um estudo que analisou a facilidade de leitura dos textos de 4.533 fatos relevantes divulgados nos anos de 2002 a 2006 pelas companhias de capital aberto. O método Flesch é definido conforme Equação 1:

$$
206,835-(1,015 \times \text { ASL })-(0,846 \times \text { ASW })
$$

Em que: ASL corresponde à quantidade média de palavras por frases e ASW a quantidade média de sílabas por palavras, chegando a índices de 0 a 100, e quanto maior for o valor, mais legível é a estrutura textual.

Outra métrica utilizada para mensuração é o Dale-Chall Readability Fórmula, que, segundo Abel (2017), é baseada no princípio que, um texto escrito com palavras familiares acaba tornando-se mais apreensível à leitura e, consequentemente, melhor entendido.

Abel (2017) também cita a métrica FORCAST fórmula, que foi desenvolvida por um estudo comissionado pelas Forças Armadas Americanas, com a finalidade de medir o nível de apreensibilidade do material de trabalho do exército, por esses materiais possuírem uma linguagem muito técnica. Essa métrica, segundo Dubay (2004), é a favorita para mensurar a apreensibilidade de textos sem frases completas, como curtos enunciados e formulários. O resultado dessa métrica representa o nível de escolaridade para o entendimento do texto.

No presente estudo, será utilizado o índice Gunning Fog Index, que foi introduzido por Gunning (1952), sendo usado para mensurar a clareza com que os textos são apresentados, e é definido conforme Equação 2:

$$
\text { GFI }=[(\text { número de palavras/número de frases) }+ \text { número de palavras difíceis })] \text { x 0,4 }
$$

O índice GFI foi escolhido para o presente estudo pois de acordo com Gunning (1952), esse índice, também conhecido como "índice de névoa", possui uma relação direta com o grau de compreensibilidade das informações apresentadas pelas empresas. Sendo assim, essa métrica é considerada a mais compatível com o tipo de material que será analisado nesta pesquisa.

\section{METODOLOGIA}

O estudo analisou o Relatório da Administração das empresas do segmento de papel e celulose listadas na [B³] no período de 2014 até 2018. O Relatório da Administração é um documento em que, normalmente, são explicitadas informações que tem a capacidade de interferir nas operações das empresas, como por exemplo, as expectativas de resultados futuros e planos de crescimento da empresa, assim como as informações a respeito do resultado alcançado, seja esse resultado positivo ou negativo (Iudícibus, 2004). Segundo Beuren et al. (2013, p. 57), o Relatório da Administração "é uma maneira que a Contabilidade pode utilizar na divulgação de informações menos estruturadas, inclusive as relacionadas às questões ambientais.”

As empresas do setor de papel e celulose listadas na $[\mathrm{B}]^{3}$ e analisadas nessa pesquisa são apresentadas na Figura 03. Destaca-se que a seleção foi não probabilística definida por meio da acessibilidade aos dados.

Figura 3 - Empresas do setor de Papel e Celulose listadas na $\mathrm{B}^{3}$

\begin{tabular}{c|c}
\hline Razão Social & Nome de Pregão \\
\hline Celulose Irani S. A. & Celul Irani \\
Cia Melhoramentos de São Paulo & Melhor SP \\
Klabin S.A. & Klabin S/A \\
Santher Fab de Papel Sta Therezinha S.A. & Santher \\
Suzano Holding S.A. & Suzano Hold \\
Suzano S.A. & Suzano S.A. \\
\hline
\end{tabular}

Fonte: B3 (Brasil, Bolsa, Balcão).

Para mensurar o nível de evidenciação de informações ambientais dessas entidades foi utilizada a combinação de dois procedimentos metodológicos de dois estudos anteriores distintos. As categorias analisadas foram definidas a partir da NBC-T 15 - Informações de Natureza Social e Ambiental, utilizadas em forma de questionamentos, como no estudo de Freitas e Strassburg (2007), que procurou também mensurar a evidenciação ambiental de empresas do setor de papel e celulose. Essas categorias foram buscadas nos relatórios divulgados pelas empresas por meio de palavras-chaves, observando também o contexto em que essas palavras se encontravam. A metodologia de identificação de informações por palavras-chave foi a utilizada por Meurer et al. (2017), ao analisarem a evidenciação de investimentos em capital humano nos Relatórios de Administração das melhores empresas para trabalhar. 
Na Figura 04 são mostradas as categorias, em forma de questionamentos, assim como as palavras-chave buscadas nos relatórios divulgados. Destaca-se que as palavras-chave foram definidas a partir dos tipos de informações definidas na NBC-T 15 - Informações de Natureza Social e Ambiental.

Figura 4 - Categorias para mensuração do índice de evidenciação

\begin{tabular}{|c|c|c|}
\hline & Categorias de análise (questionamentos) & Palavras-chave \\
\hline 1 & $\begin{array}{c}\text { Apareceram gastos de restabelecimento de áreas } \\
\text { degradadas? }\end{array}$ & $\begin{array}{l}\text { Restabelecimento, reflorestamento, área(s), degradação/ } \\
\text { degradada(s), reposição, recomposição, reestruturação }\end{array}$ \\
\hline 2 & $\begin{array}{l}\text { Foram efetuados gastos com prevenção e melhoria do meio } \\
\text { ambiente? }\end{array}$ & Prevenção, preservação, preventivo, melhoria, benfeitoria \\
\hline 3 & Foram efetuadas provisões de danos que poderão ocorrer? & Provisão(ões), dano(s) futuros \\
\hline 4 & É informado sobre os resíduos químicos? & Resíduo(s), químico(s), dejeto(s), sobra(s) \\
\hline 5 & $\begin{array}{l}\text { Investimentos e gastos com educação ambiental para } \\
\text { comunidade interna e externa? }\end{array}$ & $\begin{array}{c}\text { Educação ambiental, conscientização, escolarização, } \\
\text { mobilização, social }\end{array}$ \\
\hline 6 & É Informado sobre Passivos e Contingências ambientais? & Passivo(s) ambientai(s), contingência(s) \\
\hline 7 & $\begin{array}{c}\text { Gastos e investimentos com processos adm., judiciais e } \\
\text { ambientais movidos contra a entidade? }\end{array}$ & Processo(s), administrativo(s), judiciário, multa(s) \\
\hline 8 & Valor das multas aplicadas contra a entidade? & Multa(s), penalização, penalidade \\
\hline 9 & As informações são comparativas com anos anteriores? & Ano(s), anterior(es) \\
\hline 10 & As informações citam metas futuras na área ambiental? & Futuro, objetivo(s), meta(s), projeto(s), perspectiva(s) \\
\hline
\end{tabular}

Fonte: Adaptado de Freitas e Strassburg (2007) e a NBC-T 15 - Informações de Natureza Social e Ambiental.

Após localizar as informações evidenciadas, para cada categoria foi atribuída uma nota variando de 0 a 3 tendo como parâmetro o tipo de evidenciação apresentada. As notas foram atribuídas a partir da forma como essas evidenciações foram identificadas, conforme a Figura 05, e a soma das notas de cada categoria formaram a nota final do nível de evidenciação das empresas em cada período.

Figura 5 - Atribuição de nota para a forma de apresentação da evidenciação ambiental.

\begin{tabular}{c|c}
\hline Tipo de evidenciação de informação & Nota atribuída para mensuração do nivel \\
\hline Informação não evidenciada & 0 \\
Informação evidenciada de forma qualitativa & 2 \\
Informação evidenciada de forma quantitativa monetária & 3 \\
\hline Informação evidenciada de forma quantitativa monetária e de forma qualitativa & \\
\hline
\end{tabular}

Fonte: Adaptado com base em Rover et al. (2008).

Após localizar cada palavra-chave foi realizada a leitura, julgamento e categorização das informações contidas nos relatórios, a fim de pontuar o contexto no qual as palavras se relacionavam, podendo assim, observar se as palavras encontradas respondiam aos questionamentos apresentados nas categorias de análise. Quanto maior o nível de evidenciação, maior foi a pontuação da empresa. A partir desse processo foi obtida a primeira variável da pesquisa, ou seja, o nível de evidenciação.

A segunda variável da pesquisa consiste no índice de legibilidade. Para tanto, foi calculado o índice Gunning Fog Index. Esse índice diz respeito à legibilidade de estruturas textuais, e expressa a relação entre o número de palavras por frase, somada ao percentual de palavras consideradas pela ferramenta como complexas. Multiplicando o valor dessa soma por 0,4, se obtém o índice Gunning Fog Index de legibilidade de uma estrutura textual (Lo et al., 2017). 
Na Figura 06 são apresentados os graus de dificuldade da estrutura textual avaliada a partir do Gunning Fog Index.

Figura 6 - Requisitos linguísticos para a legibilidade

\begin{tabular}{c|c|c}
\hline Métrica & Pontos & Nível de dificuldade \\
\hline & Menos de 15 & Bom \\
Gunning's Fog Index & 15 a 20 & Médio \\
& Maior que 20 & Ilegível \\
\hline
\end{tabular}

Fonte: Adaptado de Soler et al. (2019).

Por fim, após a coleta e quantificação dos documentos analisados, foi verificada a possível relação entre a nota obtida no nível de evidenciação de custos e investimentos ambientais e o grau de legibilidade a partir da técnica de regressão linear simples operacionalizada por meio do software SPSS Statistics 19.0. O modelo testado é apresentado na Equação (3):

Em que:

$$
\mathrm{GL}_{\mathrm{i}}=\alpha+\beta_{1} \cdot \mathrm{NE}_{\mathrm{i}}+\varepsilon_{\mathrm{i}}
$$

$\mathrm{GL}_{\mathrm{i}}=$ Grau de legibilidade

$\alpha=$ Constante

$\mathrm{NE}_{\mathrm{i}}=$ Nível de evidenciação

$\varepsilon_{\mathrm{i}}=$ Erro

\section{ANÁLISE DOS RESULTADOS}

Essa seção tem como finalidade apresentar, discutir e analisar os resultados encontrados com base nas metodologias aplicadas no estudo. A análise em questão, foi realizada tanto de forma descritiva, quanto inferencial. A partir dos resultados encontrados, é possível discutir a relação entre os valores descobertos, assim como indagar sobre os possíveis motivos do comportamento das variáveis constatadas.

O nível de evidenciação e o grau de legibilidade atribuídos as empresas a partir do Relatório da Administração entre os anos de 2014 a 2018 são apresentados na Tabela 1.

Tabela 1 - Notas atribuídas aos Relatórios da Administração

\begin{tabular}{c|c|c|c|c|c|c|c|c|c|c|c|c}
\hline & \multicolumn{2}{|c|}{$\mathbf{2 0 1 4}$} & \multicolumn{2}{c|}{$\mathbf{2 0 1 5}$} & \multicolumn{2}{c|}{$\mathbf{2 0 1 6}$} & \multicolumn{2}{c|}{$\mathbf{2 0 1 7}$} & \multicolumn{2}{c|}{$\mathbf{2 0 1 8}$} & \multicolumn{2}{c}{ MÉDIA } \\
\hline EMPRESA & GL & $\mathbf{N E}$ & $\mathbf{G L}$ & $\mathbf{N E}$ & $\mathbf{G L}$ & $\mathbf{N E}$ & $\mathbf{G L}$ & $\mathbf{N E}$ & $\mathbf{G L}$ & $\mathbf{N E}$ & GL & $\mathbf{N E}$ \\
\hline Irani & 17,25 & 6 & 19,34 & 6 & 18,95 & 6 & 19,39 & 6 & 17,71 & 7 & 18,53 & 6,2 \\
Cia SP & 25,08 & 0 & 25,08 & 3 & 23,99 & 2 & 25,51 & 3 & 28,04 & 1 & 25,54 & 1,8 \\
Klabin & 21,31 & 14 & 22,52 & 12 & 22,25 & 12 & 22,24 & 8 & 22,15 & 9 & 22,09 & 11 \\
Santher & 24,53 & 2 & 22,89 & 2 & 21,67 & 2 & 22,12 & 2 & 21,24 & 2 & 22,49 & 2 \\
Holding & 22,53 & 0 & 23 & 0 & 22,89 & 0 & 22,51 & 0 & 22,52 & 0 & 22,69 & 0 \\
Suzano & 21,52 & 2 & 20,71 & 1 & 22,89 & 3 & 23,49 & 3 & 23,23 & 4 & 22,37 & 2,6 \\
\hline
\end{tabular}

Nota. GL = Grau de legibilidade; NE = Nível de evidenciação; Irani = Celulose Irani S.A.; Cia SP = Cia Melhoramentos de São Paulo; Santher $=$ Santher Fabricação de Papel de Sta Therezinha S.A.; Holding = Suzano Holding S.A.

Fonte: Elaborado pelos autores.

Algumas informações podem ser interpretadas a partir dos dados expostos na Tabela 1. Referente ao ano de 2014, não houve evidenciação de custos ou investimentos ambientais em nenhuma das categorias analisadas pelas empresas Cia Melhoramentos de São Paulo e Suzano Holding S.A. Os Relatórios da Administração dessas empresas tiveram seu foco direcionado a resultados operacionais e financeiros. Esses documentos apresentaram escassez de informações fundamentais para investidores e financiadores em geral. Em contrapartida, a empresa Klabin S.A. apresentou em 2014 tanto informações qualitativas, quanto quantitativas monetárias, no que diz respeito ao reflorestamento das áreas degradadas e educação ambiental, esta última com foco para o uso consciente dos recursos naturais, tanto para os colaboradores, quanto para a comunidade na qual a empresa está inserida.

No que diz respeito ao grau de legibilidade, os índices se apresentaram elevados. Gunning (1952) cita que, estruturas textuais com índices de grau de legibilidade Gunning Fog Index acima de 17, exigem uma graduação concluída 
para sua adequada compreensão. A empresa Cia Melhoramentos de São Paulo apresentou índice acima de 25 em seu Relatório da Administração.

Com relação ao exercício social de 2015 é possível destacar a evolução na evidenciação ambiental por parte da empresa Cia Melhoramentos de São Paulo, que passou a evidenciar em seu Relatório da Administração, de forma qualitativa, informações referente a reflorestamento de áreas degradadas, desembolsos com prevenção e melhoria do meio ambiente, e também informações sobre os resíduos químicos gerados a partir de suas atividades operacionais. Por outro lado, a Klabin S.A. deixou de apresentar suas metas futuras relacionadas ao meio ambiente, a qual evidenciou no ano anterior de forma quantitativa monetária. Na empresa Celulose Irani S.A. a pontuação de evidenciação manteve-se estável, porém com um grau superior em 2 pontos de legibilidade em relação a 2014.

Em 2016, apesar de ter deixado de informar os dispêndios com prevenção e melhoria no meio ambiente, a Klabin junto a Celulose Irani mantiveram as variáveis em valores iguais ou próximos aos anos anteriores. Por outro lado, a Suzano S. A. passou a apresentar em 2016 sua preocupação a respeito de seus resíduos químicos gerados, sendo que essa apresentação trouxe consigo o aumento do índice de legibilidade, passando de 20,71 para 22,89.

Diferentemente a 2016, no ano de 2017 a Klabin S.A. deixou de evidenciar em seu Relatório da Administração informações referentes aos resíduos químicos gerados causando diminuição considerável em seu nível de evidenciação. As demais variáveis mantiveram-se próximas às apresentadas anteriormente. A partir desse ano também é possível notar que a empresa Suzano Holding S.A. possui limitações de informações de forma geral em seus Relatórios da Administração, pois esses documentos apresentam em todos os anos analisados somente duas páginas em seus relatórios, sem direcionar atenção para evidenciações de cunho ambiental. Assim, a essa instituição foi atribuída, em nível de evidenciação, nota zero de 2014 até 2018.

Por fim, com a análise do ano de 2018 foi possível efetuar a análise histórica dos índices. De forma geral, a empresa Klabin consolidou-se como a empresa que mais evidencia informações ambientais em seu setor de atuação dentre as empresas listadas na $[\mathrm{B}]^{3}$. A Suzano Holding S.A. não apresentou em todos os exercícios sociais analisados informações referentes as questões ambientais analisadas. O maior grau de legibilidade encontrado decorreu do Relatório da Administração do ano de 2018 da empresa Cia Melhoramentos de São Paulo, sendo de 28,04, o qual demostra que a empresa se utiliza de linguagem pouco elucidativa, dificultando o entendimento por usuários leigos.

Cabe ressaltar que as empresas Celulose Irani S.A. e Suzano S.A., além das informações ambientais divulgadas nos Relatórios da Administração, publicam anualmente como complemento de informações relevantes, o Relatório de Sustentabilidade. Portanto, há possibilidade de informações não divulgadas nos relatórios analisados terem sido substituídas por informações divulgadas nos Relatórios de Sustentabilidade, não sendo consideradas neste estudo, que abrangeu somente o Relatório da Administração, que por sua vez, tem cunho de divulgação obrigatória.

Em relação ao nível de evidenciação, percebe-se que comparado ao estudo de Machado et al. (2015), à época, não foram encontradas quaisquer informações no que tange aos custos ambientais nas notas explicativas divulgadas, quando analisadas empresas do mesmo setor de atuação. O presente estudo, utilizando-se dos Relatórios da Administração obteve êxito em identificar esse tipo de informação em todas as entidades analisadas pelos dois estudos, o que cria um cenário evolutivo nessa área.

No que diz respeito ao nível de evidenciação ambiental, o estudo de Rover et al. (2008) teve como resultado a constatação de que a maior parte das informações sobre custos e investimentos ambientais foi exibida de forma quantitativa monetária. Já no presente estudo, a forma mais comum de evidenciação sobre custos e investimentos ambientais foi qualitativa. Inserindo novamente a narrativa de que as estruturas textuais se apresentam complexas no que diz respeito à compreensão por parte do usuário, sendo possível atribuir uma discussão sobre o porquê de as empresas analisadas optarem por realizar essa evidenciação de forma descritiva. A principal discussão a se apresentar seria a de que relatórios predominantemente descritivos são mais vulneráveis a manipulações e relativizações do que os relatórios predominantemente quantitativos.

Essas introspecções podem ser reforçadas quando analisado especificamente o grau de legibilidade de cada observação, conforme apresentado na Figura 07. 
Figura 07. Grau de legibilidade

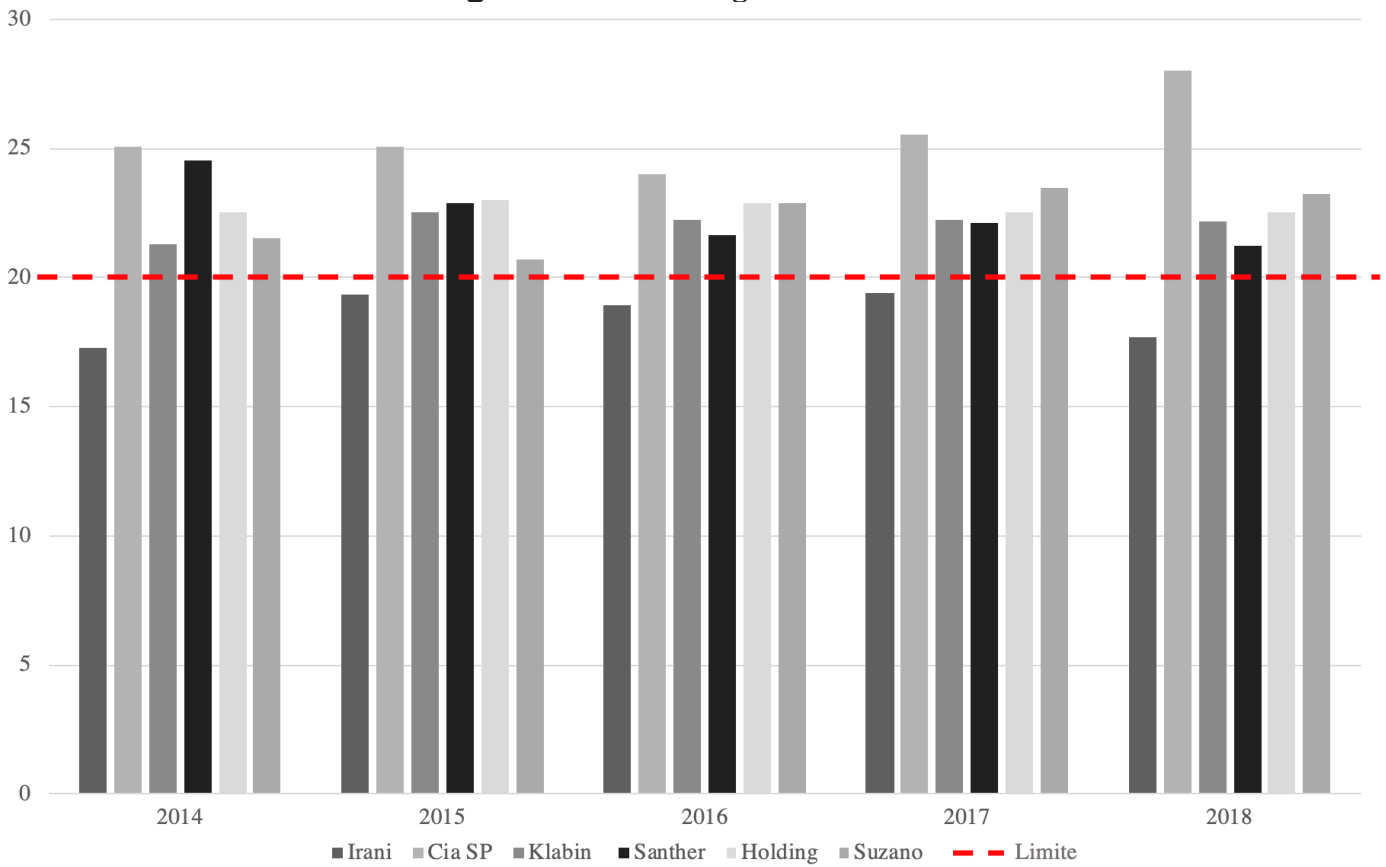

Fonte: Elaborado pelos autores.

Considerando o limite apresentado por Soler et al. (2019) nota-se que somente a Irani apresentou um grau de legibilidade considerado médio durante os anos, ou seja, oscilando entre 15 a 20 pontos. As demais organizações apresentam um grau de legibilidade acima de 20 pontos, considerado como ilegível, ou seja, exigem alta capacidade de concentração e esforço de compreensão por parte do leitor. Nesse sentido, destaca-se que a ausência de indicadores adequados de legibilidade pode implicar na baixa compreensão dos usuários da informação e prejudicar o clima de confiança existente com os stakeholders (Silva \& Fernandes, 2009; Silva \& Rodrigues, 2010).

$\mathrm{Na}$ análise da relação entre o nível de evidenciação de custos e investimentos ambientais com o grau de legibilidade, inicialmente foi verificada a adequabilidade do modelo testado após a estimação do mesmo. Em termos de parâmetros, o Fator de Inflação da Variância (VIF) foi igual a 1 indicando a ausência de alta multicolinearidade. O teste de heterocedasticidade de Breush-Pagan indicou que os resíduos são homocedástico ( $\mathrm{p}>0,05)$. Destaca-se que o software SPSS não possui a opção direta para verificação do teste de Breush-Pagan, assim tal teste foi calculado a partir dos procedimentos orientados por Fávero e Belfiore (2017). A normalidade dos resíduos foi testada por meio do teste de Shapiro-Wilk que indicou a aderência dos resíduos a distribuição normal $(p>0,05)$. Após verificar a adequação do modelo foi realizada a análise dos estimadores da regressão linear simples que são apresentados na Tabela 2.

Tabela 2 - Resultados da regressão linear simples

\begin{tabular}{|c|c|c|c|c|c|c|}
\hline & \multirow[b]{2}{*}{$\mathrm{n}=30$} & \multirow{2}{*}{\multicolumn{2}{|c|}{$\mathrm{R}^{2}=0,153$}} & \multicolumn{3}{|c|}{ ANOVA } \\
\hline & & & & \multicolumn{2}{|c|}{$\begin{array}{c}\text { Regressão = 23,431 } \\
\text { Resíduo }=129,564 \\
\text { Total }=152,996\end{array}$} & $\begin{aligned} F & =5,063 \\
\text { Sig. } & =0,032^{\star \star}\end{aligned}$ \\
\hline & \multirow{2}{*}{ Modelo } & \multicolumn{2}{|c|}{$\begin{array}{c}\text { Coeficientes não } \\
\text { padronizados }\end{array}$} & $\begin{array}{l}\text { Coeficientes } \\
\text { padronizados }\end{array}$ & \multirow{2}{*}{$\mathbf{t}$} & \multirow{2}{*}{ Sig. } \\
\hline & & $\beta$ & $\begin{array}{l}\text { Modelo } \\
\text { padrão }\end{array}$ & $\beta$ & & \\
\hline \multirow[t]{2}{*}{1} & (Constante) & 23,151 & 0,563 & & 41,120 & 0,000 \\
\hline & $\mathrm{NE}$ & $-0,231$ & 0,103 & $-0,391$ & $-2,250$ & 0,032 ** \\
\hline
\end{tabular}

Nota. ${ }^{* *}$ significante ao nível de 5\%; NE = Nível de evidenciação de custos e investimentos ambientais.

Fonte: Elaborado pelos autores. 
Os resultados indicam a existência de relação negativa entre o nível de evidenciação de custos e investimentos ambientais com o grau de legibilidade dos Relatórios da Administração das organizações. Nesse sentido, conforme o nível de evidenciação diminui há um aumento do grau de legibilidade, indicando que as empresas componentes da amostra podem utilizar linguagem mais rebuscada e complexa para suprir a falta de evidenciação de informações sobre custos e investimentos ambientais.

Healy e Wahlen (1999) alertam que, ocasionar distorções e ofuscamento de dados relevantes, por meio de alterações no grau de legibilidade pode ser classificado como gerenciamento de impressões, e pode ocorrer tanto por erro, quanto por ação do agente que transmite a informação. Por essa premissa, pode-se entender que o alto grau de legibilidade pode ser apresentado de forma proposital, tendo como uma de suas finalidades a relativização de informações relevantes que poderiam ser discorridas e melhor interpretadas se fossem apresentadas com maior nível de clareza. Dentro desse contexto, especula-se que o alto grau de legibilidade poderia inclusive alterar as expectativas do usuário da informação, pelo fato de possibilitar interpretações distintas para o mesmo texto, dependendo das habilidades do leitor.

\section{CONCLUSÃO}

Este estudo foi direcionado pelo objetivo de analisar a relação entre o nível de evidenciação de informações de custos e investimentos ambientais e o grau de legibilidade dos Relatórios da Administração de empresas do setor de papel e celulose entre os anos de 2014 a 2018. A partir dos resultados obtidos pode-se concluir que há uma evidenciação focada em elementos qualitativos de custos e investimentos nos Relatórios da Administração das empresas do setor de papel e celulose listadas na $[\mathrm{B}]^{3}$. Destaca-se também que ao longo dos anos, as empresas têm o hábito de usar consecutivamente o mesmo modelo de estrutura textual, fazendo com que o nível de evidenciação sobre custos e investimentos ambientais tenha pouca variação e evolução durante os anos.

Tal constatação é preocupante à medida que levanta dúvidas sobre a representação fidedigna a respeito da situação corrente da entidade observada. Isso pois, em grande parte dos períodos e empresas analisadas, o modelo de Relatório da Administração manteve-se padronizado, com alterações, muitas vezes, somente nos valores correspondentes a cada exercício social. O uso dessa padronização pode comprometer o discernimento sobre o verdadeiro cenário que a entidade se encontra, pelo fato do meio em que a empresa atua, ser influenciado pelo mercado, o que exige maior cuidado com a evidenciação das informações transmitidas aos stakeholders.

Ademais, os Relatórios da Administração de todas as empresas do setor de papel e celulose listadas na $\mathrm{B}^{3}$ possuem um grau de legibilidade Gunning fog Index considerado médio (GFI entre 15 e 20 pontos) ou ilegível (GFI maior que 20 pontos), tendo sua compreensibilidade comprometida. De acordo com a NBC T 1 - Estrutura Conceitual para a Elaboração e Apresentação das Demonstrações Contábeis, a compreensibilidade é uma qualidade essencial das informações apresentadas nas demonstrações contábeis para que elas sejam prontamente entendidas pelos usuários. Quando a compreensibilidade é prejudicada por elementos como a ausência de legibilidade acessível é necessário reflexões acerca da forma com que ocorre a comunicação da organização com seus diferentes stakeholders.

As empresas analisadas, em sua totalidade, evidenciam custos e investimentos ambientais. Porém, o que pôde ser constatado é que a linguagem utilizada para a evidenciação desses desembolsos pode, por ser considerada complexa, fazer com que os usuários dessas demonstrações formulem conclusões equivocadas a respeito dos custos, investimentos e resultados da empresa, principalmente naquelas com baixo grau de evidenciação. Um exemplo disso é tentar dar a impressão de que os valores dos custos ambientais são investimentos para a empresa, ao invés de despesas.

Por fim, as limitações da pesquisa consistem no pequeno número de empresas do setor de papel e celulose listadas na Brasil Bolsa Balcão, compreendendo os períodos de 2014 a 2018. As conclusões da pesquisa limitam-se a amostra e ao período analisado. Sugere-se, em pesquisas futuras outros procedimentos metodológicos, como outra métrica e fórmula para se chegar no grau de legibilidade, o uso de diferentes categorias e ferramentas para se chegar no nível de evidenciação, assim como direcionar a pesquisa para mais de um tipo de relatório, como notas explicativas ou relatórios de sustentabilidade, ou também o estudo de instituições de outros setores de atividade.

\section{REFERÊNCIAS}

Abel, F. A. (2017). Análise textual automática: apreensibilidade e qualidade da informação na área da saúde. Universidade de Caxias do Sul - UCS.

Beuren, I. M., dos Santos, V. \& Gubiani, C. A. (2013). Informações ambientais evidenciadas no relatório da administração pelas empresas do setor elétrico listadas no ISE. Revista Base (Administração e Contabilidade) da UNISINOS, 10(1), 55-68.

Borges, A. D., Rosa, F. D., \& Ensslin, S. R. (2010). Evidenciação voluntária das práticas ambientais: um estudo nas grandes empresas brasileiras de papel e celulose. Produção On Line, 20(3), 404-417.

Brasil. (2000). Lei n ${ }^{\circ}$ 10.165/2000 - Altera a Lei no 6.938, de 31 de agosto de 1981, que dispõe sobre a Política Nacional do Meio Ambiente, seus fins e mecanismos de formulação e aplicação, e dá outras providências. Recuperado em 02, jun., 2020 de http://www. planalto.gov.br/ccivil_03/Leis/L10165.htm

Bremenkamp, F. H., Almeida, J. E. F. D., \& Pereira, M. M. A. M. (2011). Análise do disclosure relacionado a acidentes ambientais da Petrobras após a Lei no 11.638/07. Sociedade, Contabilidade e Gestão, 6(3), 67-83. 
Casagrande, M. D. H., Corrêa Filho, J. C., \& Uhlmann, V. O. (2013). Custos Ambientais: Identificação, reconhecimento e evidenciação em uma empresa do setor elétrico. In Anais do Congresso Brasileiro de Custos-ABC, Uberlândia. Anais...[...] Uberlândia: 2016, Associação Brasileira de Custos. Recuperado em 02, jun. 2020, de https://anaiscbc.emnuvens.com.br/anais/article/view/172/172

Clarkson, P. M., Li, Y., Richardson, G. D., \& Vasvari, F. P. (2008). Revisiting the relation between environmental performance and environmental disclosure: An empirical analysis. Accounting, organizations and society, 33(4-5), 303-327.

Conselho Federal de Contabilidade (CFC). Norma Brasileira de Contabilidade

- NBC T-15 - Informações de Natureza Social e Ambiental Recuperado em 02, jun. 2020, de http://www.cfc.org.br/sisweb/sre/ docs/RES_1003.doc

Cruz Junior, H. (2018). Legibilidade de notas explicativas em empresas de capital aberto no Brasil. Trabalho de Conclusão de Curso. Bacharelado em Ciências Contábeis. Universidade Federal de Uberlândia, Uberlândia, MG. Recuperado em 17, ago. 2019, de https:// repositorio.ufu.br/handle/123456789/21809.

Dias Filho, J. M., \& Nakagawa, M. (2001). Análise do processo da comunicação contábil: uma contribuição para a solução de problemas semânticos, utilizando conceitos da teoria da comunicação. Revista Contabilidade \& Finanças, 12(26), 42-57.

Du, S., \& Yu, K. (2020). Do Corporate Social Responsibility Reports Convey Value Relevant Information? Evidence from Report Readability and Tone. Journal of Business Ethics, 1-22.

Dubay, W. H. The (2004). Principles of Readability. Impact Information, Costa Mesa, California.

Fávero, L. P., \& Belfiore, P. (2017). Manual de análise de dados - Estatística e Modelagem Multivariada com Excel®, SPSS® e Stata®. Rio de Janeiro: Elsevier.

Fonseca, D., Machado, D. G., da Costa, A. A., \& de Souza, M. A. (2016). Evolução da Evidenciação de Custos Ambientais: um Estudo em Empresas do Setor de Papel e Celulose-Integrantes do Índice de Sustentabilidade Empresarial-ISE. Revista de gestão ambiental e sustentabilidade, 5(2), 34-48.

Freitas, C. C. de O.; Strassburg, U. (2007). Evidenciação das informações ambientais nas demonstrações contábeis de empresas do setor de papel e celulose brasileiras. In VI Seminário do Centro de Ciências Sociais Aplicadas de Cascavel, Cascavel. Anais...[...] Cascavel: 2007, Universidade do Oeste do Paraná - UNIOESTE. Recuperado em 02, jun. 2020, de https://docplayer.com.br/8153068-Evidenciacao-das-informacoes-ambientais-nas-demonstracoes-contabeis-de-empresas-do-setor-de-papel-e-celulose-brasileiras.html

Gunning, R. (1952). The Technique of Clear Writing. McGraw-Hill.

Healy, P. M.; Wahlen, J. M. (1999). A review of the earnings management literature and its

implications for standard setting. Accounting Horizons. Sarasota, 13(4), 365-383.

Instituto Brasileiro de Governança Corporativa (IBGC). (2015). Código das melhores práticas de governança corporativa (5 $5^{a}$ ed.). Recuperado em 02, jun. 2020, de https://edisciplinas.usp.br/pluginfile.php/4382648/mod_resource/content/1/Livro_Codigo_Melhores Praticas GC.pdf.

Iudícibus, S. de. (2004). Teoria da Contabilidade. 7 ed. São Paulo: Atlas. 221-247.

Li, F. (2008). Annual report readability, current earnings, and earnings persistence. Journal of Accounting and economics, 45(2-3),

Lo, K., Ramos, F., \& Rogo, R. (2017). Earnings management and annual report readability. Journal of Accounting and Economics, 63(1), $1-25$.

Lourenço, D. A. (2011). Tipografia para livro de literatura infantil: desenvolvimento de um guia com recomendações tipográficas para designers. UFPR, Curitiba.

Lupton, E. (2003). An Exact Science. Business Source Premie, 57(5), 22.

Machado, D. G., Oliveira, A. F. D., Toledo Filho, J. R., \& Costa, A. A. D. (2015). Evidenciação de custos ambientais: um estudo multicaso de empresas do segmento de papel e celulose listadas na BM\&FBOVESPA. Revista Sinergia, 19(2), 77-90.

Machado, D. P., \& Ott, E. (2015). Estratégias de legitimição social empregadas na evidenciação ambiental: um estudo a luz da Teoria da Legitimidade. Revista Universo Contábil, 11(1), 136-156.

Meurer, A. M., Lopes, I. F., \& Musial, N. T. K. (2017). Evidenciação de Investimentos em Capital Humano nos Relatórios da Administração das Melhores Empresas para Trabalhar. Revista Eletrônica de Estratégia \& Negócios, 10(3), 149-177.

Rezaee, Z., \& Tuo, L. (2019). Are the quantity and quality of sustainability disclosures associated with the innate and discretionary earnings quality?. Journal of Business Ethics, 155(3), 763-786.

Ribeiro, M. D. S. (2005). Contabilidade ambiental. Editora Saraiva.

Rover, S., \& Borba, J. A., Borgert, A. (2008). Como as empresas classificadas no índice de sustentabilidade empresarial (ISE) evidenciam os custos e investimentos ambientais? Revista Custos e Agronegócio, 4(1), 2-25.

Rover, S., Tomazzia, E. C., Murcia, F. D. R., \& Borba, J. A. (2012). Explicações para a divulgação voluntária ambiental no Brasil utilizando a análise de regressão em painel. Revista de Administração, 47(2), 217-230.

Silva, C. A. T., \& Fernandes, J. L. T. (2009). Legibilidade dos fatos relevantes no Brasil. Revista de Administração Contemporânea-RAC Electronica, 3(1), 142-159.

Silva, C. A. T., \& Rodrigues, M. M. G. (2010). A Relevância do Relatório da Administração. Revista de Informação Contábil, $4(1), 41-56$ 
Silva, M., Theis, V., \& Schreiber, D. (2016). Análise dos investimentos e custos ambientais de uma indústria de alimentos para animais. In Anais do Congresso Brasileiro de Custos-ABC, Porto de Galinhas. Anais...[...] Porto de Galinhas: 2016, Associação Brasileira de Custos. Recuperado em 02, jun. 2020, de https://anaiscbc.emnuvens.com.br/anais/article/view/4072

Soler, C. C., Fillol, A. G., Tuesta, Y. N., \& Feliu, V. R. (2019). The environmental information report in the annual accounts: An analysis of the main ports in Spain. Harvard Deusto Business Research, VIII(3), 219-228.

Tinoco, J. E. P., \& Kraemer, M. E. P. (2011). Contabilidade e gestão ambiental. Contabilidade e gestão ambiental: Atlas. 